\title{
A Functional Analysis of Mathematics Learning Support Platform - Including Utilization of AI -
}

\author{
국내외 수학 학습지원 플랫폼의 기능 분석 \\ - 인공지능의 활용을 포함하여 - \\ Soo-Cheol Kim ${ }^{1}$ \\ 김수철 ${ }^{1}$ \\ ${ }^{I}$ Professor, Department of Mathematics Education, Daegu Catholic University, Korea, \\ sck0211@gmail.com
}

\begin{abstract}
In this study, the functions of on-line platforms are analyzed to provide implications for 'building a mathematics learning support system using artificial intelligence technology'. A total of 21 platforms developed in the United States, New Zealand, China, Japan, and Korea were analyzed. The researcher selected domestic and foreign mathematics learning support platforms that are easy to access and utilize AI as the target of analysis. For detailed analysis, the researcher directly accessed and checked the various functions of each platform. Based on the results of the primary analysis, the functions and characteristics of each platform were arranged in a table, and the secondary criteria for analysis were established using this table. The results were entered in the set analysis criteria table, and the representative cases that served as the basis for the analysis were saved in the document as a picture file. Finally, the researcher reviewed the analysis results, and synthesized and organized the user interfaces and functions of each platform using the PMI technique. As a result of the study, the functions to be installed in the mathematics learning support platform using AI in the future, improvements and considerations for platform development, and points to be considered when developing a platform utilizing AI were derived.
\end{abstract}

Keywords: AI, Artificial Intelligence, Mathematics, Learning Support, Platform, Functional Analysis

요약: 본고에서는 '인공지능기술을 활용한 수학 학습지원 시스템 구축' 에 대한 시사점을 제공하기 위하여 국내외 수학 학습지원 플랫폼의 기능을 분석하였다. 분석 대상은 미국, 뉴질랜드, 중국, 일본, 대한민국에서 개발된 온라인 플랫폼 총 21건이다. 연구자는 접근이 용이하고 AI 기술을 활용 중인 국내외 수학 학습지원 플랫폼을 분석 대상으로 선정하였으며, 상세한 분석을 위하여 플랫폼에 직접 접속하여 각 플랫폼의 다양한 기능을 직접 확인하는 것을 원칙으로 하였다. 1 차 분석 결과를 토대로, 각 플랫폼의 기능과 특징을 표로 정리하였으며, 이 표를 활용하여 2 차 분석 준거를 설정하였다. 설정된 분석 기준표에 결과를 입력하고 분석의 근거가 되는 대표 사례는 그림 파일로 문서에 저장하였다. 최종적으로, 연구자는 분석 결과를 검토하고 각 플랫폼의 사용자 인터페이스 및 기능들을 PMI 기법을 활용하여 종합하고 정리하였다. 분석 결과를 토대로, 향후 인공지능을 활용한 수학 학습지원 플랫폼에 탑재해야 할 기능들, 플랫폼 개발 시 유의해야 할 사항들, 플랫폼 개발 시 고려해야 할 AI 기술의

Received: June 03, 2021; $1^{\text {st }}$ Review Result: July 20, 2021; $2^{\text {nd }}$ Review Result: September 06, 2021 Accepted: October 31, 2021 
활용 방안 등을 제안하였다.

핵심어: $\mathrm{AI}$, 인공지능, 수학, 학습지원, 플랫폼, 기능 분석

\section{1. 들어가며}

최근 교육 분야에서 교수자의 역할은 '지식의 전수자' 에서 '안내 및 조력자(facilitator)' 로 변화되고 있으며, 현장의 교사들도 이러한 변화의 흐름을 인식하고 교수 방법의 다양화를 시도하고 있다. 변화에 잘 대처하고 창의 융합적인 인재 양성을 위하여 노력하는 교사들은 정론화된 수학 지식을 학생들에게 전달하기보다는 실생활 맥락을 수업에 도입하고 학습자들의 발견학습을 유도하며 탐구 활동을 통해 지적 호기심을 자극하는 학생 중심형 교수 방법을 지지할 것이다. 그러나 아직도 변화를 거부하는 교사들이 깨 있다는 사실을 우리는 인정할 수밖에 없다. 인공지능의 등장으로 인해 지식 전달자로서의 교수자의 역할보다는 조력자로서의 역할이 강조되는 변화의 흐름 속에서도, 문제의 풀이과정을 칠판에 빼곡하게 채우고 수학 개념을 전달하는 것이 최선이라고 믿는 교사들에게 ‘수포자(수학 포기 학생)' 는 어쩌면 외면하고 싶은 대상일지도 모른다. 물론 수포자를 줄이기 위해 매시간 노력하고 방과후에도 물심양면으로 학생들을 열심히 지도하는 교사들을 볼 때면 경외감이 드는 것도 사실이다. 그렇다고 국가나 교육청 차원의 행재정적인 지원 없이 교사들에게만 모든 수고를 강요할 수는 없다.

우리는 현장에서 수포자를 쉽게 찾을 수 있고, 그 문제의 심각성도 인식하고 있으며, 이에 대처하기 위한 학습지원 시스템이 턱없이 부족하다는 것에 충분한 공감대를 형성하고 있다. 교사들은 학생들의 수학 학습 결손이 어디에서부터 시작되었는지에 대한 원인을 위계에 따라 파악하고 이를 정확하게 진단할 수 있어야 하며, 학습결손을 파악하였다면 학습 위계에 따라 보정교육을 실시하는 것도 필요하다[1]. 하지만 학급 당 학생 수가 과다하고 교사의 수가 부족한 현실에서 교사들의 희생만으로는 근본적인 문제가 해결되지는 않을 것이다.

이러한 문제점을 해결하고자 최근 교육부에서는 ‘수학교육 종합계획(2020.5.27.)' 을 발표하였으며, 이 계획에는 '수포자 없는 교실, 실생활 문제해결력 함양, 수학 핵심 인재 양성' 등을 수학교육의 주요 목표로 설정하였다. 교육부와 한국과학창의재단은 이 교육 종합계획을 통해 인공지능, 가상 및 증강 현실 등 최첨단 에듀테크 기술을 교육 현장에 본격적으로 도입하겠다고 언급하였으며, 인공지능을 활용한 수학 학습지원 시스템 구축을 통해 정확한 학습 진단 및 맞춤형 학습을 제공하여 학생들이 수학을 포기하지 않고 즐겁게 학습할 수 있도록 지원할 예정이라고 강조하였다[2].

인공지능을 활용한 수학 학습지원 시스템을 제대로 구축하기 위해서는 국내외 관련 사례를 조사하여 현장 적용가능성을 면밀히 검토할 필요가 있으며, 교육수요자의 요구를 시스템 구축에 적극 반영할 필요가 있다. 따라서 국내외 수학 학습지원 온라인 플랫폼의 현황을 분석하고 인공지능 기술이 학습지원에 어떻게 활용되고 있는지를 면밀히 검토할 필요가 있다.

본 연구에서는 향후 교육현장에 도입될 인공지능을 활용한 수학 학습지원 시스템 개발에 시사점을 제공하기 위하여 요구되는 플랫폼의 기능과 인공지능 기술이 무엇인지 
탐색하였다. 이를 위하여 국내외 수학 학습지원 플랫폼의 주요 기능을 분석함으로써 향후 개발될 수학 학습지원 시스템 개발 및 플랫폼 구축에 시사점과 아이디어를 제공하였다.

\section{2. 연구 방법}

\section{1 분석 대상}

본 연구의 목적은 국내외 수학 학습지원 플랫폼의 주요 기능을 분석하는 것이므로, 분석 대상을 국내외 온라인 수학 학습지원 플랫폼으로 선정하였다. 분석 대상은 미국 7 건, 뉴질랜드 1 건, 중국 1건, 일본 1건, 대한민국 11 건 등 총 21 건이다. 연구자는 구글(google)이나 네이버(naver) 등 검색엔진을 활용하여 'AI 수학 학습 지원 플랫폼(AI mathematics learning flatform)' 을 키워드로 검색한 다음, 접근이 용이하고 $\mathrm{AI}$ 기술을 활용 중인 플랫폼을 분석 대상으로 선정하였다. 분석 대상 개요는 [표 1]과 같다.

[표 1] 분석 대상 개요

[Table 1] Analysis Targets

\begin{tabular}{|c|c|c|c|c|}
\hline 연번 & 국가 & 플랫폼명 & 대상 & 웹사이트 주소 \\
\hline 1 & 미국 & Khan academy & 2세 12학년 & http://ko.khanacademy.org [3] \\
\hline 2 & 미국 & MATHia* & $\mathrm{K} \sim 12$ 학년 & https://www.carnegielearning.com \\
\hline 3 & 미국 & Dream Box Learning & K 8학년 & http://www.dreambox.com [4] \\
\hline 4 & 미국 & Math 180 & $\mathrm{~K} \sim 12$ 학년 & http://www.hmhco.com/products/math-180 [5] \\
\hline 5 & 미국 & Waggle & 2 8학년 & https://www.hmhco.com/programs/waggle [6] \\
\hline 6 & 미국 & Photomath & 전 연령 & https://photomath.com [7] \\
\hline 7 & 미국 & ALEKS & $\mathrm{K} \sim 12$ 학년 & https://www.aleks.com/ [8] \\
\hline 8 & 뉴질랜드 & Amy & 전 연렁 & https://www.amy.ac [9] \\
\hline 9 & 중국 & Squirrel AI Learning* & 중/고등 & http://squirrelai.com \\
\hline 10 & 일본 & Qubena* & 초등 & https://qubena.com \\
\hline 11 & 대한민국 & Dr. MATH & 초등 & https://www.drmath.co.kr [10] \\
\hline 12 & 대한민국 & Botami & 초1 2 & http://botami.io [11] \\
\hline 13 & 대한민국 & 노리스쿨수학* & 초1 고1 & https://knowre.co.kr \\
\hline 14 & 대한민국 & 마타수학 & 중/고등 & http://www.matamath.net [12] \\
\hline 15 & 대한민국 & 콴다 & 초1 고3 & https://qanda.ai/ko [13] \\
\hline 16 & 대한민국 & EBS단추 & 고등 & $\begin{array}{c}\text { https://www.ebsi.co.kr/ebs/ai/com/ai Index.e } \\
\text { bs }\end{array}$ \\
\hline 17 & 대한민국 & 대교써밋수학 & 7세 고등 & https://summit.daekyo.com/V2/math.aspx [14] \\
\hline 18 & 대한민국 & 아이스크림홈런 & 초1 중3 & https://www.home-learn.co.kr [15] \\
\hline 19 & 대한민국 & 웅징씽크빅AI수학 & 초등 & https://msmartall.wjthinkbig.com [16] \\
\hline 20 & 대한민국 & 교원빨간펜AI & 유아 초등 & http://www.kyowonedu.com [17] \\
\hline 21 & 대한민국 & 재능AI수학 & 7세 초등 & http://jei.ai [18] \\
\hline
\end{tabular}

\section{2 분석 방법}

\subsubsection{1차 분석}

상기 [표 1]에 제시된 플랫폼들의 상세한 분석을 위하여 각각의 웹사이트에 접속하여 플랫폼의 특징과 기능을 연구자와 연구보조원이 직접 조사하였다. 플랫폼 방문 조사에는 연구보조원 5명을 활용하였는데, 조사 전에 협의회(2021.04.02)를 거쳐 [표 2]와 같은 
1차 분석 샘플(sample)을 제시함으로써 연구보조원들이 조사 대상 플랫폼에 방문하여 주요 기능과 특징, 그리고 제한점 등을 일관되게 조사할 수 있도록 유도하였다.

\section{[표 2] 1차 분석 예시}

[Table 2] Primary Anlaysis Examples

\begin{tabular}{|c|c|}
\hline $\begin{array}{l}\text { UI 또는 } \\
\text { 주요 기능 }\end{array}$ & $\begin{array}{l}\text { - 문제풀이 위주의 2-10분 이내의 유튜브 영상으로 구성되어 있으며, 연습문제에서는 보통 } \\
30 \text { 문항으로 구성된 수학문제를 풀고 정답 및 풀이 과정을 확인할 수 있음 } \\
\text { - 학년 구분이 없고 PBL(Problem Based Learning) 방식 중심의 동영상 강의 방식으로 운영함 } \\
\text { - 수학 문제를 푸는 동안 자신의 선택에 따라서 적절한 힌트나 계산기를 사용하도록 함 } \\
\text { - 인공지능을 활용해서 학습자간의 질문과 답변을 하면서 각 학습자가 질문한 내용음 가장 위에 } \\
\text { 배치하도록 하여 학습자간의 상호작용을 기반으로 자기주도적 학습 및 문제해결 경험 제공함 } \\
\text { - 맞춤형 피드백을 제공하는 챗봇인 MathBot을 사용하여 개인별 수학 학습을 하도록 함 }\end{array}$ \\
\hline 특징 & $\begin{array}{l}\text { - 학습자의 수학 진도 및 성취도 취약점 등을 분석 } \\
\text { - 교사와 학생에게 향후 학습을 위한 효과적인 정보를 제공 }\end{array}$ \\
\hline 제한점 & - 한글 버전 서비스 제공하나 미국의 수학과 교육과정에 국한 \\
\hline 사이트 & http://ko.khanacademy.org \\
\hline
\end{tabular}

\subsubsection{2차 분석}

연구보조원들은 1 차 분석 결과를 플랫폼의 주요 기능, 사용자인터페이스(UI), 특징, 제한 및 기타 사항 등으로 구분하여 [표 2]와 같이 정리하였으며, 연구자는 21건의 1차 분석 자료(raw data)를 활용하여 2차 분석 기준을 [그림 1]과 같이 설정하였다.

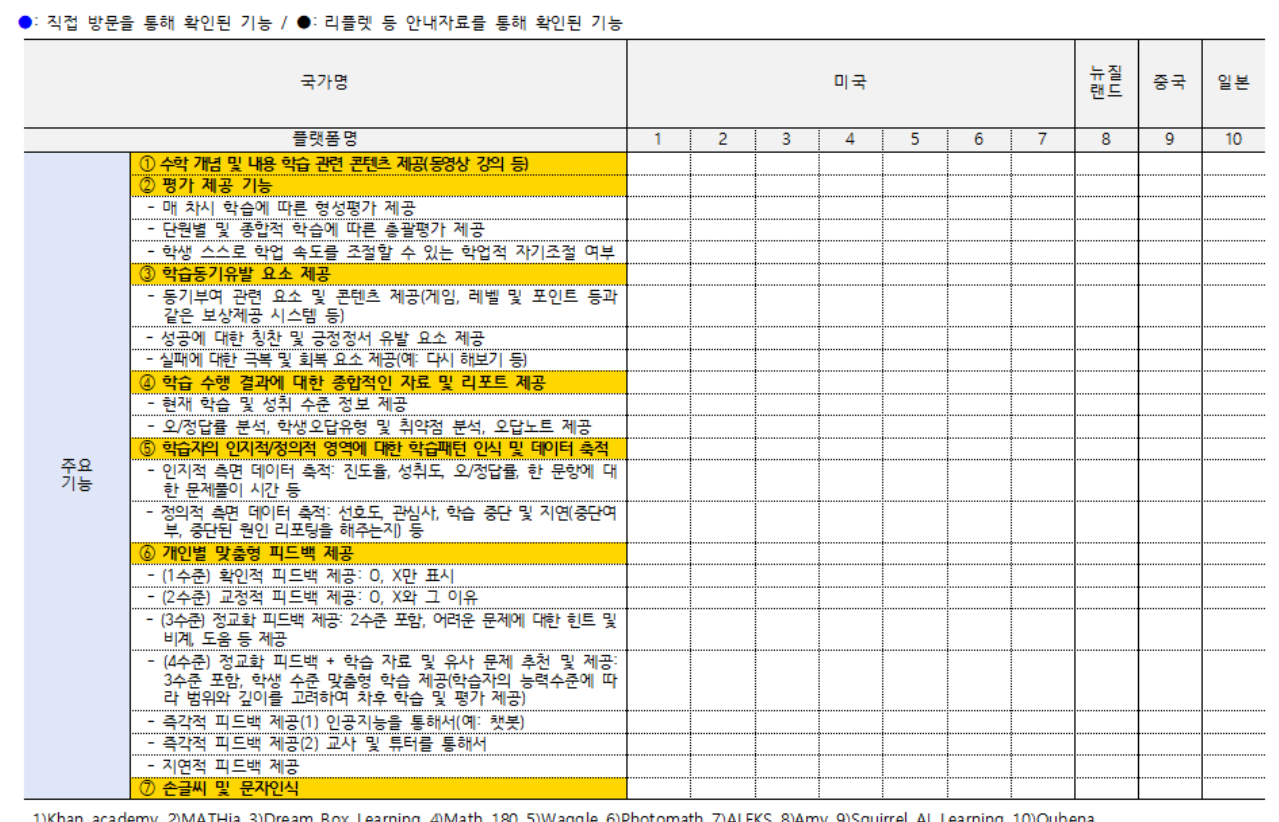

[그림 1] 2차 분석을 위한 기준

[Fig. 1] Criteria for Secondary Analysis

상기와 같이 설정된 분석 기준에 따라 연구보조원들은 다시 2 차 분석을 수행하였다. 연구보조원들은 링크된 홈페이지에 접속하여 각각의 플랫폼의 기능을 직접 확인한 후 국가, 업체, 플랫폼명, 사이트 주소, 서비스 대상, UI 또는 주요 기능, 장/단점, 기타 
사항 등을 분석하였으며, [그림 1]의 분석 기준표에 조사 결과를 입력하였다. 플랫폼의 분석은 7 가지의 주요 기능과 17 가지의 하위 기능에 대한 체크리스트를 작성하는 방식으로 수행되었는데, 각 항목에 해당되는 요소가 있을 경우 “”를 입력하였으며, 입력 근거에 대해서는 해당 사례를 캡쳐하여 그림 파일로 저장하였다. 분석 근거의 수집 사례는 [그림 2]와 같다.

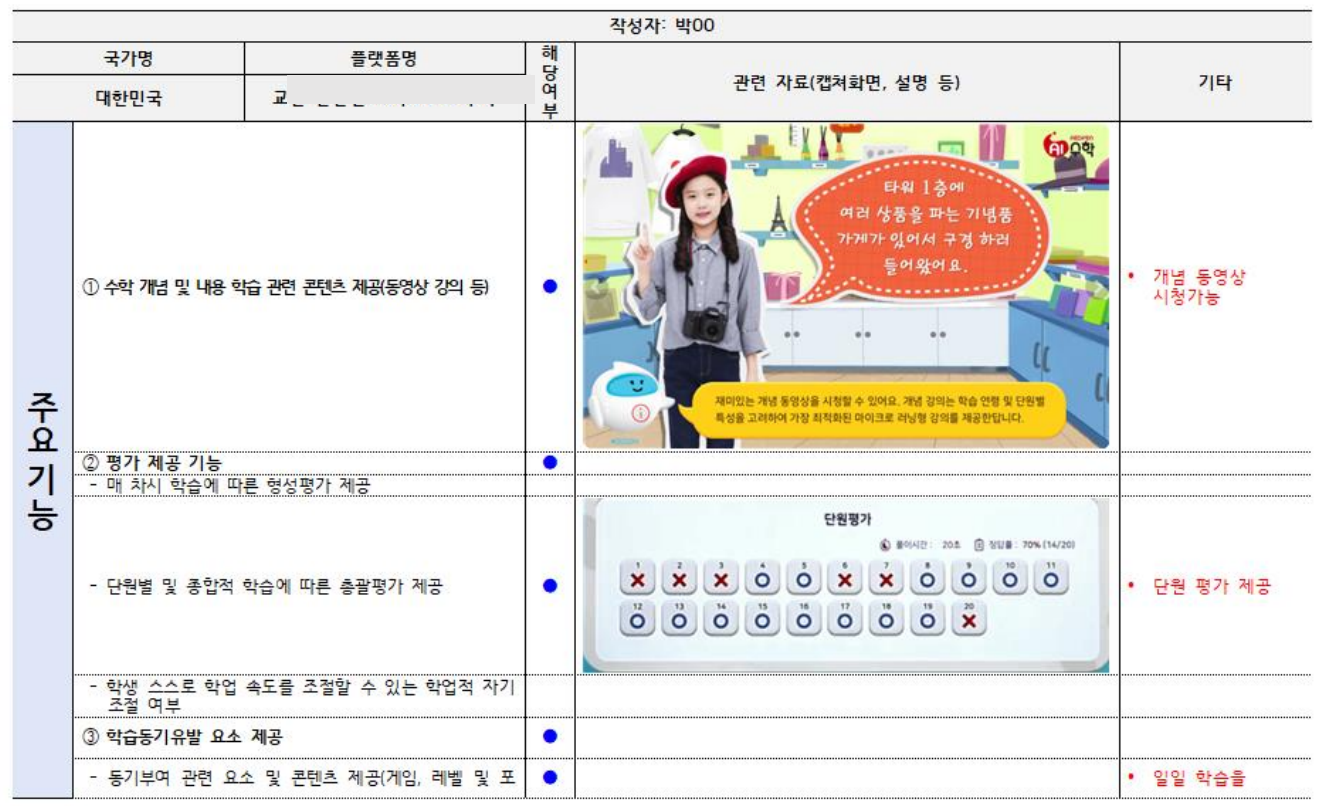

[그림 2] 분석 근거의 수집 사례

[Fig. 2] Examples of Gathering Evidence for Analysis

\section{2 .3 최종 분석 및 검토}

연구자는 2 차 분석 결과를 검토하고, PMI 기법을 활용하여 각 플랫폼의 장/단점, 특징 및 강점, $\mathrm{AI}$ 활용 실태 등을 [그림 3]과 같이 정리하였다.

\begin{tabular}{|c|c|}
\hline & 17) 대한한국 - \\
\hline $\begin{array}{l}\text { 장점 } \\
(\mathrm{P})\end{array}$ & $\begin{array}{l}\text { - 알고리즘에 맞춰서 학생 개인 맞춤형 문제가 제시됨 } \\
\text { - 학습자는 학습하기 전, 학습진도와 목표를 스스로 확인한 뒤 개념강의를 통해 기본지식을 } \\
\text { 익히는 것으로 시작하고, 문제를 푸는 단계를 거침 } \\
\text { - 오답일 경우 왜 틀렸는지 원인을 찾도록 도와주며, 관련내용을 프린트하여 담당 선생님과 } \\
\text { 면대면으로 다시 복습하는 형태로 AI와 교사의 ㅎㅕㅕ업 을 통해 완ㅈㅓㅓ항습이 가능하도록 함 } \\
\text { - 기초연산완성 과정과 교과내신완성 과정으로 학습 과정을 체계적으로 설계함 }\end{array}$ \\
\hline $\begin{array}{l}\text { 단점 } \\
(\mathrm{M})\end{array}$ & $\begin{array}{l}\text { - 사용할 수 있는 스마트기기가 태블릿으로 한정되어 있음 } \\
\text { - 힌트를 쉽게 제공해주기 때문에 학생들이 힌트에 지나치게 의존할 가능성이 있음 }\end{array}$ \\
\hline $\begin{array}{l}\text { 특징 또는 } \\
\text { 강점 } \\
\text { (I) }\end{array}$ & $\begin{array}{l}\text { - 학습보상 시스템이 잘 이루어져 있음(게임형태 학습, 학습완료 스탬프 제공, 배지와 별, 리 } \\
\text { 그전으로 함께 공부할 수 있게 하는 기능) } \\
\text { - 마스터리 매트릭스: 마스터해야 할 문제 유형과 완전 학습된 유형을 매트릭스로 시각화하 } \\
\text { 여 한눈에 성취도를 팡가하게 함 } \\
\text { - 예측 알고리즘: 학습량과 학습완료 시간을 예측하여 몰입감과 동기부여를 제공함 }\end{array}$ \\
\hline $\mathrm{AI}$ 활용 & $\begin{array}{l}\text { - 학생 개인 맞춤형 문제 제시(추천 알고리즘 활용) } \\
\text { - AI 보조교사를 활용한 복습 기능 제공 } \\
\text { - 학습량과 학습완료 시간 예측을 통한 몰입감 및 동기부여 제공(예측 알고리즘 활용) }\end{array}$ \\
\hline
\end{tabular}

[그림 3] PMI를 활용한 분석 예시

[Fig. 3] Examples of Analysis using PMI 
세 차례의 분석 결과를 토대로, 국내외 온라인 수학 학습지원 플랫폼의 AI 활용 실태를 분석하고, PMI 분석 결과를 활용하여 AI 기반의 수학 학습지원 플랫폼 구축에 관한 시사점을 도출하였다.

\section{3. 연구 결과}

\section{1 국내외 수학 학습지원 플랫폼의 주요 기능}

\subsection{1 국외의 플랫폼 분석 결과}

국외의 수학 학습지원 플랫폼의 분석 결과는 미국 7 건, 뉴질랜드 1 건, 중국 1 건, 일본 1 건 등 총 10 건이며, 3 건의 플랫폼은 접근성이 용이하지 않아 웹에서 확인가능한 리플렛이나 안내자료 등을 활용하여 분석을 수행하였다. [그림 4]는 국외의 플랫폼 분석 결과를 주요 기능별로 살펴본 것이다. 국외의 경우, 미국의 플랫폼 개발 사례가 많은 편이고 접근성도 용이하나, 중국과 일본은 그렇지 못하다.

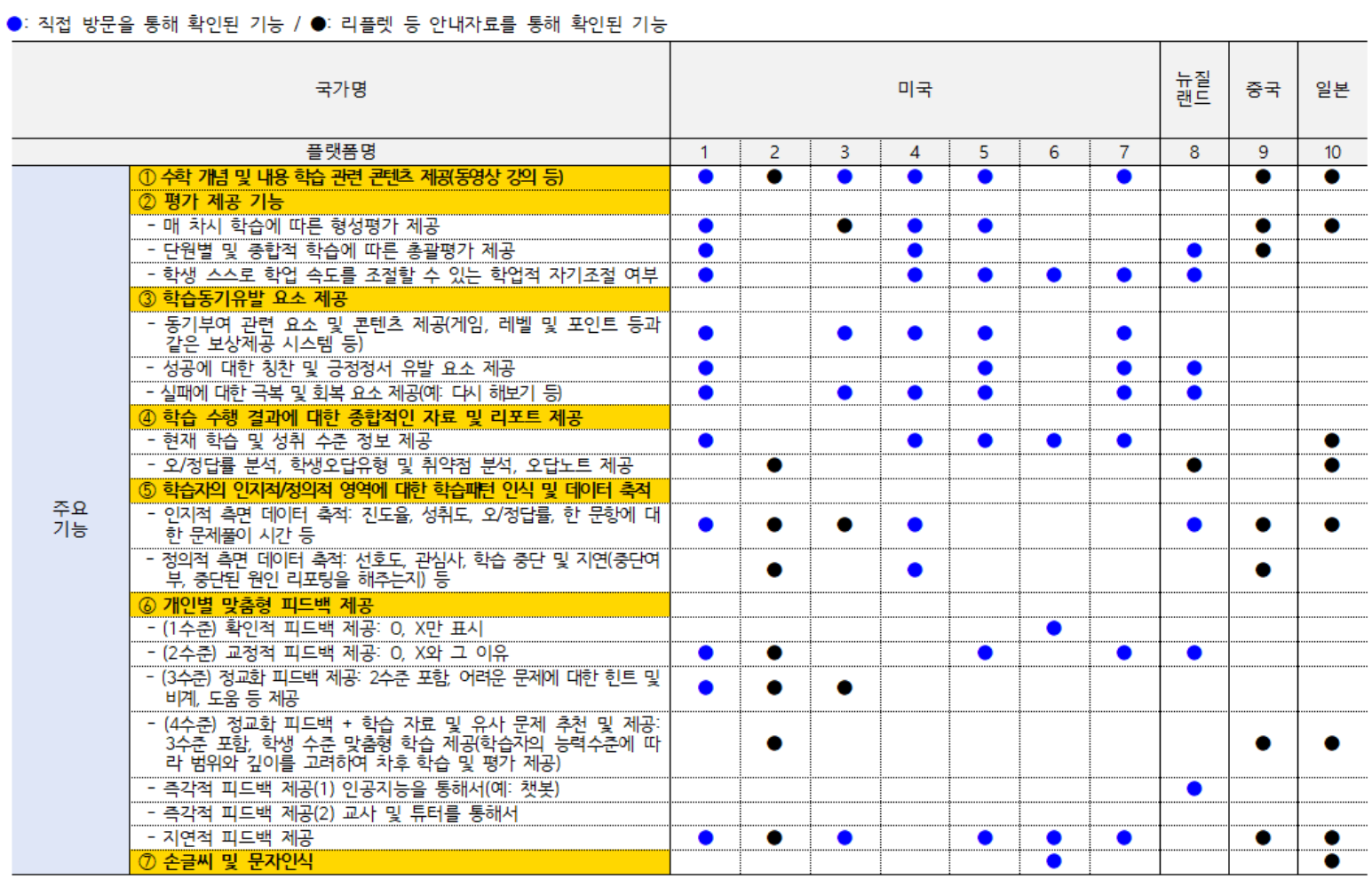

[그림 4] 국외의 플랫폼 분석 결과

[Fig. 4] Analysis of Foreign Platforms

첫째, 학습 관련 콘텐츠(contents) 제공 기능이다. 미국의 플랫폼들은 수학 개념 및 학습 관련 콘텐츠를 대부분(6/7) 제공하고 있으며, 평가 기능도 대부분(6/7)제공하고 있다. 중국과 일본의 플랫폼도 수학 개념 및 학습 관련 콘텐츠를 제공하고 있다. 뉴질랜드의 플랫폼에는 해당 기능이 없다.

둘째, 평가 기능이다. 미국의 플랫폼들은 총괄평가보다는 형성평가 제공에 무게가 실려있으며, 학생 스스로 학업 속도를 조절할 수 있는 기능을 대부분(5/7) 제공하고 
있다. 이는 평가의 기능이 학습의 결과보다 과정에 더 많은 비중을 두고 있다고 해석할 수 있다. 중국과 일본의 플랫폼은 매 $3 / 7$ 차시 형성평가를 제공하며, 중국은 총괄평가 기능도 함께 제공하고 있다. 하지만 중국과 일본 모두 학생 스스로 학업 속도를 조절할 수 있는 기능은 없다. 한편, 뉴질랜드의 경우 총괄평가 기능과 학생 스스로 학업 속도를 조절할 수 있는 기능을 제공하고 있다.

셋째, 학습동기유발 기능이다. 미국의 플랫폼들은 대부분 $(5 / 7)$ 학습동기유발 기능을 제공하고 있다. 세부적으로, 동기부여 관련 요소 및 콘텐츠 제공 비율, 실패에 대한 극복 및 회복 요소 제공 비율은 각각 $5 / 7$ 이지만, 성공에 대한 칭찬 및 긍정 정서 유발 요소 제공 비율이 $3 / 7$ 으로 낮다. 뉴질랜드의 경우 성공에 대한 칭찬 요소, 실패에 대한 극복 요소를 모두 제공하고 있다. 한편, 중국과 일본은 해당 동기유발 관련 기능이 플랫폼에 없다.

넷째, 학습 수행 결과에 대한 종합적인 리포팅(reporting) 기능이다. 미국의 플랫폼들은 대부분 $(5 / 7)$ 현재 학습 및 성취 수준에 관한 정보를 제공하고 있으나, 오/정답률 분석이나 오답유형 및 취약점 분석 기능을 제공하는 플랫폼은 거의 $(1 / 7)$ 없다. 뉴질랜드와 일본은 오/정답률 분석 및 취약점 분석 기능만, 중국은 현재 학습 및 성취 수준 정보만을 제공하고 있다.

다섯째, 학습자의 인지적/정의적 영역에 대한 학습패턴 인식 및 데이터 축적 기능이다. 미국의 플랫폼들은 인지적 영역에 대한 데이터 인식 및 축적 비율이 4/7이고, 정의적 영역은 $2 / 7$ 로 낮은 편이다. 뉴질랜드, 중국, 일본은 모두 인지적 영역에 대한 데이터만을 축적하고 있으며, 중국의 경우 정의적 영역까지 서비스를 제공하고 있다.

여섯째, 개인별 맞춤형 피드백 제공 기능이다. 이 기능은 피드백 제공 수준에 따라 4 가지로 구분할 수 있으며, 확인적 피드백(1수준: 정/오 표시로 피드백 제공), 교정적 피드백(2수준: 정/오 표시와 오답의 원인 제공), 정교화 피드백(3수준: 2 수준의 기능을 포함 및 어려운 문제에 대한 힌트 제공), 정교화 피드백을 포함한 학습자료 및 유사문제 추천(4수준: 3 수준의 기능 포함 및 수준에 따른 맞춤형 학습 콘텐츠 제공) 등이다. 한편, 피드백의 제공 시기에 따라 즉각적 피드백과 지연적 피드백으로 구분할 수 있으며, 즉각적 피드백은 인공지능 챗봇의 활용과 교사 및 튜터의 활용으로 다시 구분할 수 있다. 미국의 플랫폼들은 1 수준의 제공 비율이 $1 / 7,2$ 수준 $4 / 7,3$ 수준 $3 / 7,4$ 수준 $1 / 7$ 으로 2 수준의 피드백 제공 비율이 상대적으로 높고, 대부분(6/7) 지연적 피드백을 제공하고 있다. 뉴질랜드는 2수준의 피드백을 제공하며, 인공지능 챗봇을 통한 즉각적인 피드백을 제공하고 있다. 중국과 일본은 모두 4수준의 피드백을 제공하며, 지연적인 피드백을 제공하고 있다. 일곱째, 손글씨 및 문자인식 기능이다. 국외의 플랫폼들 중에서 손글씨 및 문자인식 기능을 제공하는 플랫폼은 미국과 일본 각각 1 건이다.

\section{1 .2 국내의 플랫폼 분석 결과}

국내의 수학 학습지원 플랫폼의 분석 결과는 총 11 건이며, 1 건의 플랫폼은 접근성이 용이하지 않아 웹에서 확인가능한 리플렛을 활용하여 분석을 수행하였다. [그림 5]는 국내의 플랫폼 분석 결과를 주요 기능별로 살펴본 것이다. 


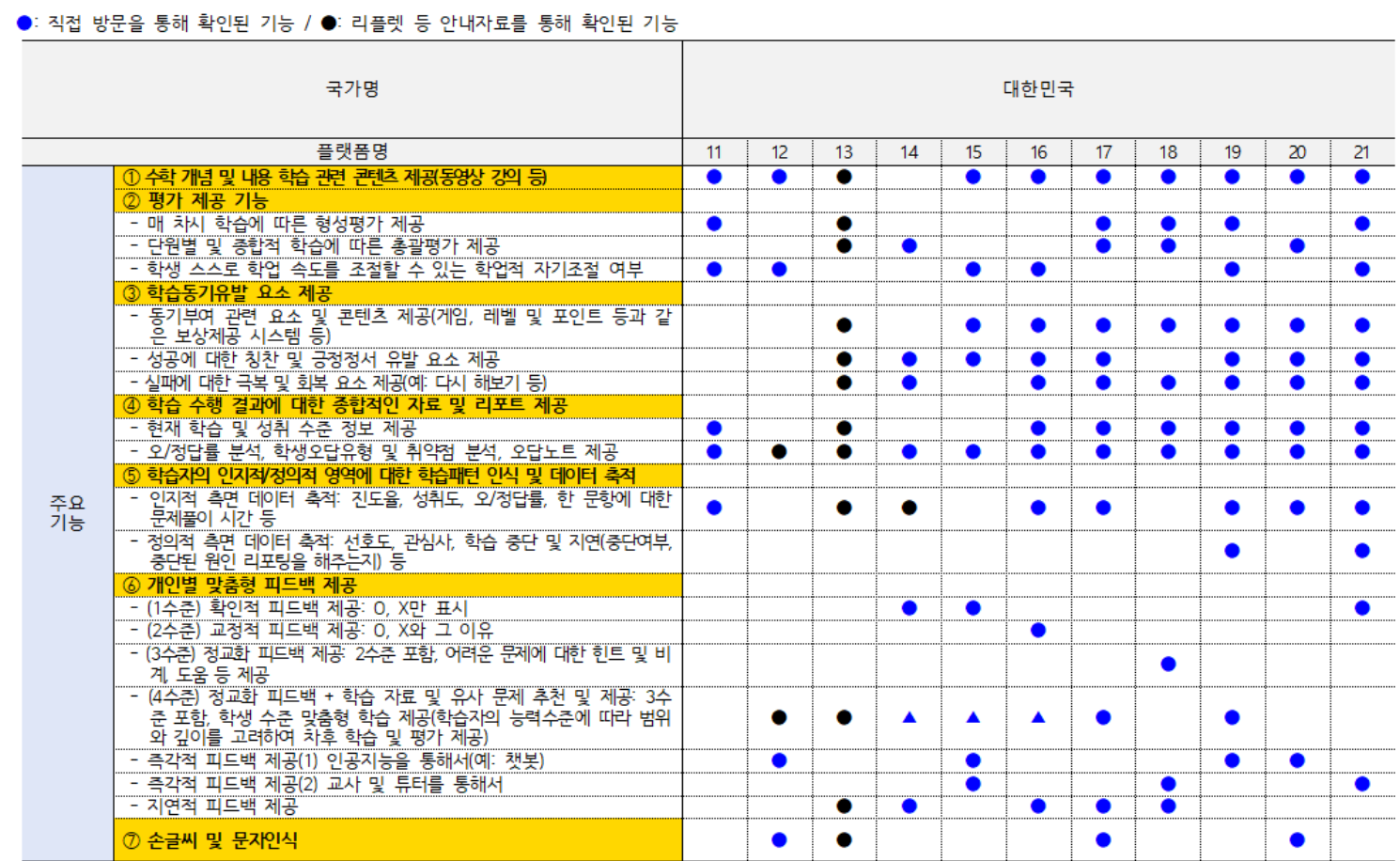

[그림 5] 국내의 플랫폼 분석 결과

[Fig. 5] Analysis of Domestic Platforms

첫째, 수학 개념 및 학습 관련 콘텐츠(contents)의 제공 기능은 국내의 대부분(10/11)의 플랫폼에 탑재되어 있다.

둘째, 평가 기능은 국내의 모든 플랫폼에서 제공하고 있다. 이 기능을 세부적으로 살펴보면, 형성평가 제공 비율이 $6 / 11$, 총괄평가 제공 비율이 $5 / 11$, 학생 스스로 학업 속도를 조절할 수 있는 기능 비율이 6/11으로, 향후 개발될 플랫폼에는 형성적 기능이나 자기 조절 기능 등을 포함하는 평가시스템, 즉 학습 과정을 평가하는 기능을 확대할 필요가 있다.

셋째, 학습동기유발 기능은 국내의 대부분(9/11)의 플랫폼에서 제공하고 있으며, 세부적으로, 동기부여 관련 요소 및 콘텐츠 제공 비율, 성공에 대한 칭찬 및 긍정 정서 유발 요소 제공 비율, 그리고 실패에 대한 극복 및 회복 요소 제공 비율이 각각 8/11로 동일하다. 즉 국내의 플랫폼은 학습동기유발 기능을 다양하게 제공하는 있는 것으로 보인다.

넷째, 학습 수행 결과에 대한 종합적인 리포팅(reporting) 기능은 국내의 모든 플랫폼에서 제공하고 있다. 세부적으로, 오/정답률 분석이나 오답유형 및 취약점 분석 기능은 모두 제공하고 있으며, 현재 학습 및 성취 수준 정보의 제공은 8/11 수준이다.

다섯째, 학습자의 인지적/정의적 영역에 대한 학습패턴 인식 및 데이터 축적 기능의 경우, 국내에서 개발된 플랫폼의 대부분 $(8 / 11)$ 이 인지적 영역에 대한 데이터를 축적하고 있으며, 정의적 영역의 데이터 축적 비율은 $2 / 11$ 로 낮은 편이다. 따라서 향후 개발될 플랫폼에는 정의적 영역의 데이터를 축적하는 방안을 적극 검토해야 할 것으로 보인다.

여섯째, 국내의 플랫폼에 탑재된 개인별 맞춤형 피드백 제공 기능은 1 수준 비율이 $3 / 11$ 이고, 2 수준 $1 / 11,3$ 수준 $1 / 11,4$ 수준 $4 / 11$ 이며, 4 수준의 피드백 제공에서 학습자료 및 유사문제의 추천 기능만을 제공하는 플랫폼의 비율은 $3 / 11$ 이다. 즉 3 수준 이상의 
정교한 피드백을 제공하는 플랫폼은 전체의 약 $45 \%$ 정도이며, 학습자료 및 유사문제의 추천 기능을 제공하는 플랫폼은 약 $64 \%$ 이다. 한편, 즉각적인 피드백을 제공하는 플랫폼의 비율은 $6 / 11$ 이며, 이 중에서 인공지능 챗봇의 활용 비율은 $4 / 11$, 교사 및 튜터를 활용한 피드백 제공 비율은 $3 / 11$ 이다. 반면, 지연적인 피드백을 제공하는 플랫폼의 비율은 5/11이다. 일곱째, 손글씨 및 문자인식 기능을 제공하는 국내의 플랫폼 비율은 4/11로 아직까지 미비한 실정이다.

\section{2 국내외 플랫폼의 PMI 분석 결과 및 인공지능 기술 활용 정도}

향후 인공지능을 활용한 수학 학습지원 플랫폼 개발에 시사점을 제공하기 위해서는 현재 운영 중인 국내외 플랫폼의 다양한 특성과 제한점, $\mathrm{AI}$ 기술의 활용 정도 등을 종합적으로 분석할 필요가 있다. 따라서 연구자는 분석 대상인 플랫폼들의 장/단점, 강점 및 특수성, $\mathrm{AI}$ 기술 활용도 등을 각 플랫폼마다 PMI 기법으로 분석하고 정리하였다.

장점 $(\mathrm{P})$ 와 강점 $(\mathrm{I})$ 는 향후 플랫폼 구축 시 사용자의 교수학습지원에 대한 만족도를 높일 수 있는 플러스 요인으로 볼 수 있으며, 단점(M)은 현재 운영 중인 플랫폼들에서 드러난 제한점을 제시한 것으로, 향후 플랫폼 구축 시 반영을 검토할 필요가 있는 마이너스 요인으로 볼 수 있다. 한편, AI 기술의 활용은 현재 인공지능 기술이 수학 학습지원 플랫폼에서 어느 정도 접목되고 있는지를 보여주는 것으로, 인공지능을 활용한 플랫폼 개발에 적용 가능한 기술을 검토하고 꼭 필요한 기술이 무엇인지를 가늠케하는 중요한 기초자료가 될 수 있다. 국내외 수학 학습지원 플랫폼들의 장점(P)과 강점(I)의 핵심적인 내용을 토대로, 플랫폼에 탑재해야 할 기능을 제시하면 다음과 같다.

- 직관적이고 조작이 쉬운 사용자 인터페이스

- 학습을 관리하고 독려하는 알람 및 푸시 기능

- 학습진도, 성취도(또는 핵심개념의 이해도), 취약점 분석 등의 인지적 영역과 학습패턴 분석, 흥미, 몰입, 자신감, 태도 등의 정의적 영역을 아우르는 종합적인 리포팅 제공 기능

- 종합적인 리포팅과 연계한 학습코칭 기능

- 동기부여 및 흥미 제공 기능(게임 형식, 포인트 적립, 선의의 경쟁 유도 등)

- 맞춤형 학습진단 및 처방, 보정학습 자료(반복학습 기능 포함) 제공 기능

- 인공지능 챗봇 서비스 : 인지적/정의적 영역에 대한 자료 수집 및 맞춤형 피드백 제공

- 인공지능 보조교사 서비스 : 채점, 실시간 피드백/튜터링, 학습진도관리, 학습결손 포착, 학습자료 추천 등

- 도형 및 그래프 그리기 등 기하 및 함수 영역에서 학습활동이 용이한 툴 제공

- 수학 학습과 관련된 실생활 자료나 영상 제공 기능

- 학습자의 손글씨(문자와 수식 포함) 인식 기능

또한, 국내외 수학 학습지원 플랫폼들의 제한점 또는 단점(M)을 토대로, 플랫폼 개발 시 유의해야 할 사항을 제시하면 다음과 같다.

- 모든 학교급 및 학년에서 활용 가능하고 접근성이 용이한 플랫폼 개발

- 과도한 힌트의 제공 지양

- 개인별 맞춤형 진단 및 피드백 기능의 정교화 
- 다양한 학습 콘테츠와 문제 제공 서비스 지향

- 정의적 영영의 진단 결과에 대한 활용 방안 모색

- 종합적인 리포팅 제공 시 프린팅 기능 추가

한편, 국내외 수학 학습지원 플랫폼들의 AI 기술 도입 실태 분석 결과를 토대로, 플랫폼 개발 시 고려해야 할 AI 기술의 활용 방안을 제시하면 다음과 같다.

- BKT(Bayesian Knowledge Tracing) 알고리즘 : 수학 학습진단에 따라 학습결손 가능성이 높은 부분을 확률적으로 제시

- 응답 최적화 API(Application Programming Interface), IALS(Intelligent Adaptive Learning System), RNN(Recurrent Neural Network) : AI 챗봇, AI 보조교사 서비스에 활용

- 머신러닝 및 딥러닝 : 플랫폼의 모든 학습활동 데이터를 누적 및 학습

- 비전인식기술(OCR) : 텍스트, 이미지, 손글씨(문자와 수식 포함) 인식률 향상으로 문제풀이와 관련된 맞춤형 피드백 제공

- Eye-tracking 기술 : 학습자의 수업참여 및 집중도 분석

- $\mathrm{QR}$ 코드 : 수학적 개념 또는 문제를 동영상이나 교재, 가상 공간과 직접 연결

- AR/VR : 수학 학습과 관련된 내용을 증강 및 가상현실을 통해 학습자의 체험을 유도

\section{4. 결론 및 제언}

본 연구에서는 미국, 뉴질랜드, 중국, 일본, 대한민국 등 5 개국에서 개발된 온라인 수학 학습지원 플랫폼을 분석하였다. 연구자는 접근이 용이하고 AI 기술을 활용 중인 국내외 수학 학습지원 플랫폼을 분석 대상으로 선정하였으며, 분석 대상은 미국 7 건, 뉴질랜드 1 건, 중국 1 건, 일본 1 건, 대한민국 11 건 등 총 21 건이다. 각각의 플랫폼 분석을 위하여 웹검색 엔진에서 검색이 가능한 국내외 온라인 학습지원 플랫폼의 웹사이트에 연구자와 연구보조원들이 접속하여 해당 플랫폼의 사용자 인터페이스 및 기능들을 직접 확인하여 특징이나 제한점, $\mathrm{AI}$ 기술 활용 정도 등을 조사하였다. 연구자는 분석을 위한 준거를 1 차 분석을 통해 설정하였으며, 설정된 분석틀에 따라 2 차 분석을 실시하고 대표 사례를 추출하여 분석의 근거로 삼았다. 또한, PMI 기법을 활용하여 국내외 플랫폼들의 장/단점, 강점 및 특수성, $\mathrm{AI}$ 활용 정도를 종합/정리하였으며, 이를 통하여 수학 학습지원 플랫폼 개발에 관한 시사점을 도출하였다.

분석 결과를 토대로, 국내외 수학 학습지원 플랫폼의 주요 서비스, AI 기술 활용 정보, 학습하기 기능, 평가 기능, 피드백 및 힌트 제공, 오답 및 취약점 리포팅, 흥미 및 동기부여, 교사용 서비스 제공, 학습과정 모니터링, 종합적 리포팅, 정의적 영역 리포팅 등으로 구분하여 제시하면 다음과 같다.

첫째, 국내외 AI 기반의 수학 학습지원 플랫폼은 개별 맞춤형 평가 및 학습 콘텐츠 제공, 챗봇 등을 활용한 대화형 피드백 제공, 문제풀이 기반의 튜터링 서비스 등을 주로 제공 하고 있다.

둘째, 국내외 플랫폼에 활용되고 있는 인공지능 기술은 BKT(Bayesian Knowledge Tracing) 알고리즘, IALS(Intelligent Adaptive Learning System), RNN(Recurrent Neural Network) 모델, OCR(Optical Character Recognition) 인식 기술, 응답 최적화 
API(Application Programming Interface), 손글씨 인식 기술, 빅데이터 분석, 추천 알고리즘, 머신러닝, 딥러닝 등이 있다.

셋째, 평가 및 진단, 학습 및 피드백 제공 기능은 진단 결과에 따른 맞춤형 수학 학습 콘텐츠 제공이 대부분이며, 소수의 플랫폼에서는 짧은 동영상 강의 콘텐츠를 제공하기도 하였다. 또한, 평가 및 진단 결과에 따른 실시간 피드백이나 힌트, 그리고 오답이나 취약점에 관한 리포팅(reporting) 정보를 제공하는 플랫폼이 대부분이며, 학습코칭 가이드를 제공하는 플랫폼도 있다.

넷째, 홍미 및 동기 부여 기능의 경우 일부는 플랫폼에서 다양한 시청각 자료나 에니메이션, 미니 게임, 게임 형식의 보상 시스템 등을 제공하고, 일부는 개별 성향에 맞는 학습 동기 부여 서비스를 제공하고 있다.

다섯째, 교사를 위한 서비스 기능은 일부 플랫폼에서 제공하고 있는데, 주로 학습 진도나 현황에 대한 실시간 정보 제공, 학생 수준 진단 및 수준별 과제 부여 기능 등이며, 시각화 리포팅 정보나 문항 출제나 채점 등에 대한 교사 연수를 제공하는 플랫폼도 있다.

여섯째, 미국을 제외한 대부분의 플랫폼에서는 학습과정 및 결과 모니터링(monitoring) 등 학습 전반에 대한 종합적인 리포팅을 제공하고 있다. 미국의 경우 일부 개발사에서만 상기의 서비스를 제공하고 있다. 반면, 정의적 영역의 리포팅 서비스의 제공 기능은 국내외 플랫폼 모두 미비한 편이다.

연구 결과를 토대로, 향후 인공지능을 활용한 수학 학습지원 플랫폼 개발에 관한 시사점을 제공하면 다음과 같다.

첫째, 교육수요자의 요구에 부응하는 효과적인 수학 학습지원 플랫폼을 개발하기 위해서는 개별 맞춤형 평가 및 학습 콘텐츠, 실시간 피드백, 종합적인 리포팅 정보 등을 적시적소에 제공할 수 있도록 다양한 인공지능 기술적용 방안을 모색하고, 사용자 인터페이스의 특성에 따라 최적의 $\mathrm{AI}$ 기술을 매칭(matching)할 수 있도록 플랫폼의 기획 단계에서부터 심도 있는 논의가 필요하다.

둘째, 수요자의 관점에서 직관적이고 조작이 쉬운 사용자 인터페이스를 개발할 필요가 있으며, 태블릿 $\mathrm{PC}$, 모바일, 데스크탑, 노트북 등 모든 기기에서 접근이 가능하도록 플랫폼을 개발할 필요가 있다.

셋째, 몇몇 플랫폼들은 학습자에게 과도한 힌트를 제공하여 학습자의 사고를 막는 사례가 발견되었으므로, 플랫폼 기획 및 개발자들은 수학의 학문적 특성을 고려하여 학습자가 충분히 사고할 수 있도록 점진적이고 단계적인 힌트를 제공할 수 있는 피드백 제공 방안을 모색할 필요가 있다.

넷째, 현재까지 국내외에서 개발된 수학 학습지원 플랫폼의 경우 정의적 영역의 리포팅 서비스 제공이 미흡한 편이므로 향후 플랫폼 개발에 정의적 영역에 대한 서비스를 어떠한 방식으로 제공할 것인지, 정의적 영역의 분석 결과를 어떻게 활용할 것인지에 대한 깊은 논의가 필요하다.

다섯째, 국내의 경우 민간 기업에서 개발된 플랫폼이 공교육에 적용된 사례가 전무하므로 이를 공교육과 연계하여 서비스를 제공하는 방안을 모색할 필요가 있다. 또한, 정부 주도의 $\mathrm{AI}$ 기반의 수학 학습지원 시스템 개발 사업이 수행된다면 정확한 현황 분석과 수요자의 니즈(needs)을 적극 반영하고 수학교육전문가 및 교사, AI 전문가, 교육학 또는 심리학 전문가의 의견을 다양하게 수렴하여 학생 및 교사에게 실질적인 도움이 될 수 있는 플랫폼이 개발되도록 많은 관심과 노력을 기울여야 할 
것이다.

\section{5. 감사의 글}

This work was supported by the National Research Foundation of Korea(NRF) grant funded by the Korea government (No. 2021R1A2C1005426).

\section{References}

[1] N. Huh, H.Y Kim, S.C. Kim, An Application of Mathematics Assessment and Correction Model According to Learning Hierarchy, School Mathematics, (2020), Vol.22, No.3, pp.671-687.

[2] Mathematics Education Plan('2020 ’2024), Ministry of Education, (2020), pp.1-23.

[3] http://ko.khanacademy.org, May 3 (2021)

[4] http://www.dreambox.com, May 3 (2021)

[5] http://www.hmhco.com/products/math-180, Jun 27 (2021)

[6] https://www.hmhco.com/programs/waggle, Jun 27 (2021)

[7] https://photomath.com, Jun 28 (2021)

[8] https://www.aleks.com/, Jun 28 (2021)

[9] https://www.amy.ac, May 4 (2021)

[10] https://www.drmath.co.kr, May 7 (2021)

[11] http://botami.io, May 7 (2021)

[12] http://www.matamath.net, Jun 30 (2021)

[13] https://qanda.ai/ko, Jun 30 (2021)

[14] https://summit.daekyo.com/V2/math.aspx, Jun 27 (2021)

[15] https://www.home-learn.co.kr/main/Index.do, Jun 29 (2021)

[16] https://msmartall.wjthinkbig.com, Jun 28 (2021)

[17] https://www.kyowonedu.com/KEP/PRD/KEPPrdInfo.jsp?prdtCd=LRNRPN004, Jun 28 (2021)

[18] http://jei.ai, Jun 30 (2021) 